\title{
Risk MANAGEMENT OF PENSION Systems FROM THE PERSPECTIVE OF LOSS AVERSION
}

\author{
JOHANNES BINSWANGER
}

\section{CESIFO WORKING PAPER NO. 1572}

CATEgory 1: Public FinANCE

OCTOBER 2005 


\title{
RisK MANAGEMENT OF PENSION SYSTEMS FROM THE PERSPECTIVE OF LOSS AVERSION
}

\begin{abstract}
This paper studies pension design from a risk management point of view using a lexicographic loss aversion model. Interest in this model stems from the fact that it explains income expansion paths of equity and total savings particularly well. I find that all income groups are likely to benefit from a PAYGO system, even in the absence of any redistribution. Optimal equity investments are close to zero for the two bottom income quintiles and increase sharply for higher incomes. The results are compared to optimal pension plans under HARA preferences. I find that a PAYGO system has higher value under loss aversion than in the HARA case. Moreover, equity shares correspond more closely to empirical observations.
\end{abstract}

JEL Code: H55.

Keywords: pension system, portfolio choice, income heterogeneity, loss aversion, HARA preferences.

\author{
Johannes Binswanger \\ Institute for Industrial Economics \\ University of Social Sciences \\ Manufacture des Tabacs, Bât F \\ 21 allée de Brienne \\ 31000 Toulouse \\ France \\ binswanger@wwi.unizh.ch
}

I am grateful to Michele Boldrin, Peter Diamond, Richard Disney, Armin Falk, Josef Falkinger, Ernst Fehr, Reto Föllmi, Dennis Gärtner, Volker Grossmann, Manuel Oechslin, Panu Poutvaara, Eytan Sheshinski, Andreas Wagener, Richard Zeckhauser, Josef Zweimüller and seminar participants at the University of Zurich, the Budapest Workshop on Behavioral Economics, the University of Mannheim, the CESifo Area Conference on Public Economics and the CEBR/CESifo Conference on Pension Reform for very helpful comments. I am responsible for all remaining errors. 


\section{Introduction}

Many recent pension reform proposals have been heavily influenced by rate-of-return comparisons between alternative retirement systems. A prominent example is President George W. Bush's current reform plan for the US. (See for example Shiller, 2005a, for a detailed description.) Decreasing birth rates as well as increasing longevity have shifted the implicit returns of a pay-as-you-go (PAYGO) system downwards. As a result, the popularity of funded systems has increased substantially. Besides the issue of transition, the focus on rate-of-return comparisons neglects, however, that different pension systems imply very different risk exposures of old-age income. In particular, a PAYGO system might provide a beneficial downside risk protection of old-age income. A more complete analysis of optimal pension design therefore requires an evaluation of the risk-return trade-offs that are associated with the choice between particular pension designs.

A factor which complicates the evaluation of such risk-return trade-offs is income heterogeneity. Empirically, members of the two lowest quintiles of the income distribution typically hold portfolios, including private pensions, with zero equities. In contrast, members of the fifth quintile choose portfolios with an equity share of about 54 percent (see Section 6). The model that is predominantly used in the literature to evaluate risk-return trade-offs is the constant relative risk aversion (CRRA) model. However, this model predicts constant equity shares. Thus, it is at odds with the cross-section of risk-return evaluations that individuals reveal through their private portfolio choices. The policy implications derived under CRRA preferences are therefore problematic.

The aim of this paper is to study optimal pension design such that the evaluation of risk-return trade-offs is consistent with the cross-section of individual portfolio choices. Within the family of expected utility preferences, Stone-Geary or more general HARA preferences offer an alternative accounting for an increasing pattern of equity shares. The problem with these preferences is that they have difficulties to explain quantitatively individuals' equity portfolio shares and total saving rates at the same time. ${ }^{1}$ Moreover,

\footnotetext{
${ }^{1}$ See Binswanger (2005). Calibrations for alternative utility and parameter specifications not presented
} 
expected utility models are generally not consistent with the fact that equity holdings are zero for the two lowest income quintiles. ${ }^{2}$ The same is true for existing models of habit formation or loss aversion. ${ }^{3}$

The lexicographic loss aversion model developed in Binswanger (2005) explains stockmarket nonparticipation of the bottom income quintiles in a simple and parsimonious way. Beyond this, it explains entire income expansion paths of equity shares and total saving rates particularly well. For these reasons, the main part of the analysis of this paper abandons the assumption of expected utility preferences, making use of this lexicographic loss aversion model. However, for the sake of comparison, I also derive optimal pension plans for various HARA specifications. Beyond its empirical success, interest in the lexicographic loss aversion model arises for two reasons. First, loss aversion has been found an empirically important phenomenon. (But remember that, in contrast to the lexicographic model, existing loss aversion models are not consistent with zero equity holdings of low-income earners.) Second, the model is particularly tractable. ${ }^{4}$

From a more general perspective, this paper aims to take a first step towards the realization of a research program put forward by Poterba (2004) in the context of oldage provision. He makes the claim that "future work should (...) try to develop tractable alternatives to the expected utility framework, and to calibrate these alternatives in a way that could be used to evaluate household decision making (p. 50)." It might seem odd to there are available upon request.

${ }^{2}$ See Haliassos (2002) for an excellent survey. See also Section 6 of this paper. Fixed costs of stockmarket participation allow to account for zero stock holdings of lower-income earners. However, such fixed costs lead to the prediction of discontinuous income expansion paths for equity shares, which are not observed empirically.

${ }^{3}$ See Gomes and Michaelides (2003) and also Haliassos (2002).

${ }^{4}$ For HARA preferences formulas for the portfolio problem with three risky assets, that is at the core of the analysis of this paper, are given in Cass and Stiglitz (1970). They are relatively cumbersome. Moreover, accounting for zero equity shares for lower incomes would require introducing fixed costs of stock-market participation. Taking these into account, together with nonnegativity constraints, the problem becomes analytically rather untractable. This is true all the more for existing models of habit formation or loss aversion. 
use a "behavioral" model, exhibiting loss aversion, for a normative evaluation of old-age provision and pension design. However, this would only be inconsistent if the meaning of "behavioral" is understood as "irrational." Are loss aversion preferences irrational? Kahneman and Tversky (1991, p. 1057) conclude that this is not the case whenever actual experiences indeed correspond to the feeling of loss aversion. I adopt this position, accepting from a normative point of view that people legitimately are particularly averse to outcomes that undercut some specific consumption threshold levels.

This paper follows the approach of Baxter and King (2001), Campbell et al. (2001), Poterba et al. (2003), Poterba (2004) and Gollier (2005) by considering pension design from the perspective of an individual portfolio choice problem in a partial equilibrium setting. My analysis departs from this literature in that I do not assume CRRA preferences. Furthermore, I explicitly derive optimal contribution rates for a PAYGO system, exploring whether such a system is particularly beneficial in the presence of loss aversion.

To focus on the role of income heterogeneity and loss aversion, the analysis takes place in a simple two-period setting. Individuals can invest in bonds and stocks. In addition to these private investment opportunities, they can "invest" in a hypothetical "PAYGO asset." I derive optimal expenditure shares for these three investments opportunities. In order to realize an optimal policy, a social planner would implement a mandatory PAYGO system where contribution rates are set equal to the expenditure shares of hypothetical PAYGO investments.

The returns of the PAYGO system, as considered in this paper, are determined simply by the growth rate of aggregate wages. The idea is to focus on a PAYGO system in its purest form where all return risks are borne by retirees and there are neither benefit guarantees nor is there any intragenerational redistribution. Ultimately, the goal is to shed light on the question of whether a system with less generous benefit guarantees than current systems will provide a sustainable reform option. By design, systems without benefit guarantees are not exposed to the danger of a "cost explosion" as a consequence of low fertility rates. ${ }^{5}$

\footnotetext{
${ }^{5}$ The formal analysis abstracts from political risks affecting the payouts of a PAYGO system. This
} 
The main findings are as follows. Under loss aversion, a PAYGO system in the manner described above generally offers a more favorable downside risk protection of old-age income than bond investments. This is true even in the absence of redistribution and for the entire range of incomes. In contrast, only the two highest income quintiles will benefit from a funded component with substantial equity investments. To put these results into perspective, I also provide calibrations for HARA preferences. The main differences are the following. First, a PAYGO system has higher value under loss aversion. Second, prescribed equity shares correspond more closely to individuals' actual portfolio choices under lexicographic loss aversion preferences.

The rest of the paper is organized as follows. Section 2 discusses the empirical downside risk of alternative pension investments. Section 3 introduces a baseline version of the lexicographic loss aversion model. Section 4 explores the conditions under which a PAYGO system is beneficial and provides calibrations for optimal pension plans under baseline preferences. Section 5 presents calibrations for an extended version of those preferences, taking into account a more general shape of risk aversion. Section 6 compares the results from the two lexicographic models to optimal pension plans under HARA preferences. Section 7 concludes.

\section{Downside Risk of Alternative Pension Components}

This section provides descriptive evidence regarding the downside risks of alternative means of old-age provision. The focus on downside risk is motivated by the fact that, due to loss aversion, this risk component is a first-order issue for a behaviorally oriented analysis of risk management. As described in the introduction, I focus on a PAYGO system in its purest form where the returns are simply given by the growth rate of aggregate wage income. The geometric average of real annual wage income growth has been 3.6 percent for the US from 1929 to 2004. The corresponding standard deviation amounts is justified in a first step exactly by the absence of any benefit guarantees, assuring the viability of the PAYGO system. 
to 5.5 percent. ${ }^{6}$ For real bond returns, measured as an average of money market rates and long-term bond returns, the geometric mean has been 1.6 percent with a standard deviation of 6.1 percent for the same time period. ${ }^{7}$ For stocks the corresponding figures are 6.1 and 19.0 percent. $^{8}$

These figures are not too informative with regard to downside risk exposures for two reasons. First, future growth rates of aggregate wage income are expected to fall well below historical rates. Second, the precise implications of the different standard deviations for downside risks are unclear. Therefore, I calculate bottom percentiles of the respective return distributions cumulated over a time horizon of 32 years. ${ }^{9}$ Concerning PAYGO

\footnotetext{
${ }^{6}$ Data source: NIPA Table 1.10. Aggregate wage income is measured by compensation of employees and deflated by the GDP deflator.

${ }^{7}$ Throughout the paper, I use historical returns of nominal bonds as a proxy for future returns rather than returns of inflation protected bonds such as TIPS. The reason is that there is very little historical knowledge regarding the range of returns of the latter. Their current $(08 / 01 / 05)$ long-term returns are about 2 percent p.a. (source: US Department of the Treasury). Thus, they exceed the historical average of real returns of ordinary bonds. However, if anything, in an equilibrium the returns of TIPS should be lower than the expected returns of ordinary bonds because the former are not exposed to inflation risk.

${ }^{8}$ Data source for bond and stock returns: Shiller (2005b) and http://www.irrationalexuberance.com/ ShillerSocSec.xls.

${ }^{9}$ Under the assumption that working age lasts from age 21 to 65 and death takes place at age 87 (see below), the time horizon of 32 years corresponds to the average length of individuals' investment horizon. To see this note that 32 equals the distance between the middle of 65 and 87 and the middle of 21 and 65 , minus one. The subtraction of one year refers to the assumption that savings are invested at the end of a particular year during working age, but are withdrawn at the beginning of a particular year during retirement. The death age of 87 corresponds to the projected average life-expectancy of men and women at age 65 for the year 2080 (Board of Trustees, 2005). The joint distribution of bond, stock and PAYGO returns is derived as follows. It is assumed that logs of annual returns are jointly normal and iid. This is a usual assumption which guarantees that net level returns are never lower than minus 100 percent (or gross level returns never fall below zero). The means of annual log returns are set equal to the arithmetic averages of historical annual log returns minus .5 times their respective variances (where historical returns are adjusted for the PAYGO system as described in footnote 10). This assures that the expected values of annual level returns correspond to the geometric averages of historical returns. The covariance matrix of $\log$ returns is set equal to the covariance matrix of historical log returns. Means and the covariance
} 
returns, I assume that the distribution of aggregate wage income growth is shifted downwards such that expected annual growth rates correspond to long-run projections of the Social Security Administration for the growth rates of productivity and the labor force. ${ }^{10}$ The standard deviation is left unadjusted.

Figure 1 depicts the cumulated 32-year return levels corresponding to the ten lowest percentiles. The red solid line corresponds to the PAYGO system. The green dashed and blue dotted line represent bond and stock returns, respectively. For each percentile, the curves indicate a return level that is undercut with a probability equal to the value of this respective percentile. E.g. returns corresponding to the fifth percentile are undercut with a probability of 5 percent. The lower a return level corresponding to a certain percentile, the higher is the downside risk exposure of the respective return distribution.

Inspection of Figure 1 shows that the downside risk exposure of the PAYGO system is very limited in comparison to bonds and stocks. For example, for the fifth percentile, the PAYGO return equals 2 percent, whereas bond and stock returns equal minus 8 and minus 31 percent, respectively. To put these figures into perspective, note that expected 32-year returns equal 77, 69 and 659 percent for the PAYGO system, bonds and stocks, respectively. What is surprising is the large difference between the downside risk exposures of PAYGO and bond returns. This is especially true in light of the fact that the level of PAYGO returns has been adjusted downwards according to projections for future wage income growth. The downside risk of stocks is still considerably larger than for bonds. The rest of the paper explores optimal pension design in light of the downside risk exposures shown in Figure 1 as well as the expected returns associated with alternative pension components.

matrix of log returns for a period of 32 years simply equal 32 times the annual log means and covariance matrix, respectively. 1,000,000 log return realizations are randomly drawn from the 32-year distribution and converted to level returns to determine return percentiles (and the correlations used in Section 5).

${ }^{10}$ For the long-run the Social Security Administration projects an annual productivity growth rate of 1.6 percent and a growth rate of the labor force of 0.2 percent for the intermediate scenario. (See Board of Trustees, 2005, Table V.B1 and V.B2. Short-run projections are higher.) I take these figures to infer a future expected annual growth rate of aggregate wage income of 1.8 percent. 


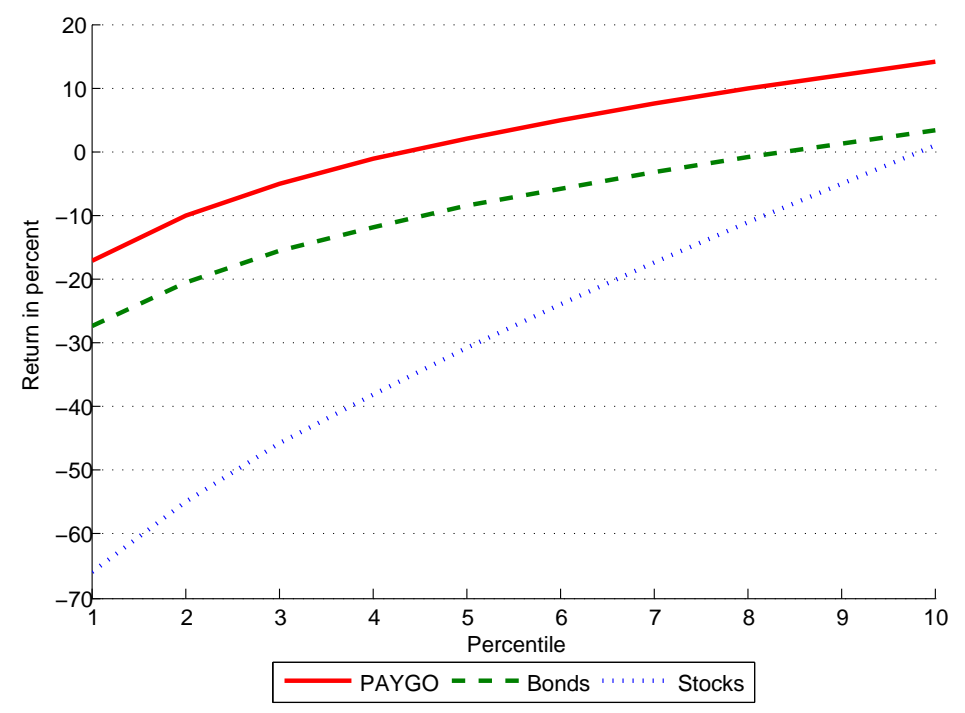

Figure 1. Downside risk of PAYGO system, bonds and stocks.

\section{Lexicographic Loss Aversion Preferences: A Base- line Specification}

This section introduces lexicographic life-cycle preferences as developed in Binswanger (2005). These preferences are specified in an extreme way, as (infinite) loss aversion is the only source of risk aversion. This represents a limit case of some possibly richer preference structure. It provides a simple approximation to actual evaluations of risky consumption prospects. In spite of their extreme nature, these preferences explain individuals' portfolio and savings choices surprisingly well, indicating that they indeed capture some fundamental principle of risk evaluations. Moreover, this baseline preference version allows studying the implications of loss aversion for optimal risk management separately from diversification issues. Section 5 will introduce an augmented version of lexicographic preferences allowing for a more general shape of risk aversion.

According to Binswanger (2005) preferences are lexicographic over the list

$$
\Pi=\left\{I\left(\tilde{c}_{2}^{\min } \geq \alpha c_{1}\right), \min \left[c_{1}, \bar{c}\right], E \tilde{c}_{2}\left(c_{1}-\bar{c}\right)^{\gamma}\right\}
$$

which constitutes a list of three hierarchically ordered "goals" that a decision maker seeks 
to achieve. $c_{1}$ and $\tilde{c}_{2}$ represent working age and retirement consumption, respectively. The tilde indicates that retirement consumption is risky as it depends on the outcome of risky investments. $\tilde{c}_{2}^{\text {min }}$ denotes the minimum of old-age consumption. In the setting that will be considered, it is assured that a strictly positive value of $\tilde{c}_{2}^{\min }$ is always feasible. $\alpha>0, \bar{c}>0$ and $\gamma>0$ are the three parameters of the model. $I$ denotes the indicator function. $E$ denotes the mathematical expectation operator.

Individual behavior is determined by the maximization of element or goal $i$ in (1), subject to achieving the maximum of all elements/goals with an index smaller than $i$, and subject to the budget constraint. Consider the first goal. It takes a value of one whenever $\tilde{c}_{2}^{\text {min }} \geq \alpha c_{1}$, and of zero otherwise. Consequently, individuals are infinitely loss averse as they will never choose a consumption plan for which it is not assured that at least a fraction $\alpha$ of working-age consumption can be consumed during retirement. I will refer to the reference point $\alpha c_{1}$ as a habit level. Note that the first goal can always be fully achieved whenever there is an asset with a minimum gross return that strictly exceeds zero (meaning that the net return exceeds minus 100 percent).

Consider next the second goal, which embodies the desire to achieve an average standard of living $\bar{c}$. Put differently, $\bar{c}$ represents an exogenous reference point for the evaluation of $c_{1} \cdot{ }^{11}$ Combining the first and the second goal it follows that an individual maximizes $c_{1}$ s.t. $\tilde{c}_{2}^{\text {min }} \geq \alpha c_{1}$ and the budget constraint, as long as income is sufficiently low such that the resulting optimal choice of $c_{1}$ does not exceed $\bar{c}$. Otherwise, satiation of the first two goals is feasible. In this case, behavior is determined by the third goal, which is residual in nature. It specifies a desire for "speculative" savings in the sense of a preference for high expected levels of old-age consumption. Beyond this, it specifies nonsatiation in $c_{1}$ and a complementarity between $c_{1}$ and $E \tilde{c}_{2}$. Subtracting $\bar{c}$ from $c_{1}$ assures that $c_{1}$ is a strictly normal good at all income levels. Note that $\gamma$ simply represents the

\footnotetext{
${ }^{11}$ See Binswanger (2005) for a more thorough discussion. Note that the first goal implies that $\tilde{c}_{2}$ is implicitly evaluated against a reference point $\alpha \bar{c}$ parallel to $c_{1}$ being evaluated against $\bar{c}$. Clearly, average standards of living increase over time. The analysis of this paper abstracts from economic growth, however, such that such a time-dependence is neglected.
} 
inverse of a standard discount factor. To see this take logs of the third goal. If behavior is determined by the third goal, individuals maximize $E \tilde{c}_{2}\left(c_{1}-\bar{c}\right)^{\gamma}$ s.t. $c_{1}>\bar{c}, \tilde{c}_{2}^{\min } \geq \alpha c_{1}$ and the budget constraint.

\section{Optimal Pension Plans: Baseline Case}

As described in the introduction, optimal pension design is analyzed from the perspective of an individual portfolio choice problem, where the distribution of bond, stock and PAYGO returns is taken as exogenously given. I consider a hypothetical environment where individuals can freely decide how much to invest in bonds, stocks and a "PAYGO asset." The returns of the latter are given by the growth rate of aggregate wages. Thus, there is no intragenerational redistribution. Optimally chosen expenditure shares for hypothetical PAYGO investments correspond to the optimal contribution rates that a social planner would set for a real mandatory PAYGO system in the absence of intragenerational redistribution. In a stationary state of the economy, any generation would benefit from the presence of such a mandatory system.

The first part of this section is concerned with a purely theoretical analysis of the conditions under which a PAYGO system beneficially contributes to risk management. It will be explored whether these conditions vary between different income classes. The second part of this section provides a calibration of optimal old-age provision.

\section{Does a PAYGO System Beneficially Contribute to Risk Manage- ment?}

Let us start the analysis by introducing some notation. Gross bond returns are denoted by $\tilde{x} \in[\underline{x}, \bar{x}]{ }^{12}$ Gross stock returns are denoted by $\tilde{y} \in[\underline{y}, \bar{y}]$. Similarly, gross PAYGO returns are denoted by $\tilde{z} \in[\underline{z}, \bar{z}]$. Consistent with the evidence in Section 2, I assume that bond returns have a higher minimum return but also a lower expected return than

\footnotetext{
${ }^{12}$ Note that gross returns equal net returns plus 1 (or plus 100 percent).
} 
stocks. Moreover, I assume that the same is true for the PAYGO asset. ${ }^{13}$

Assumption 1 (i) $\underline{x}>\underline{y}, E \tilde{x}<E \tilde{y}$, (ii) $\underline{z}>\underline{y}, E \tilde{z}<E \tilde{y}$.

The position of the PAYGO asset with respect to bonds on the risk-return scale is left open at this point. Next, I assume that there is a positive probability that all three assets will take their minimum value.

Assumption $2 \operatorname{Pr}[\tilde{x}=\underline{x}, \tilde{y}=\underline{y}, \tilde{z}=\underline{z}]>0$.

This assumption excludes that diversification can increase the minimum return of a portfolio. As it is plausible to expect that returns on all three assets are particularly low within some "catastrophic" state of the economy, this is a natural assumption.

Denote bond investments by $b$, stock investments by $s$ and PAYGO investments by $p$. A final assumption rules out the possibility of borrowing and short-selling.

Assumption $3 b \geq 0, s \geq 0, p \geq 0$.

This is a realistic assumption for all but the highest incomes and is therefore important to be taken into account.

Let us start the analysis by considering optimal portfolio plans for lower incomes. Note that information about minimum and expected returns is generally sufficient for the derivation of optimal portfolios under preferences (1). Consider an individual with an income $w$ that is smaller or equal to $\frac{\alpha+\max [\underline{x}, \underline{z}]}{\max [\underline{x}, \underline{z}]} \bar{c} \equiv w^{\text {crit }}$. Let us hypothesize that only the first two goals in (1) are active for this income range. As discussed in Section 3, optimal choices are then determined by the program

$$
\max c_{1} \text {, s.t. } \tilde{c}_{2}^{\min }=\alpha c_{1} .
$$

\footnotetext{
${ }^{13}$ From a purely theoretical point of view, minimum gross returns are zero (or minimum net returns minus 100 percent) for any financial asset, as there is some small but positive probability that economies will enter into a disastrous state such as a war. From a more pragmatic point of view, one will identify "minimum" returns with return levels that are exceeded with a high probability, e.g. 95 percent.
} 
It follows directly from this program that the individual will only invest in the asset with the highest minimum return. (Note that $\tilde{c}_{2}^{\min }=b \underline{x}+s \underline{y}+p \underline{z}$. ) This allows her to assure habit consumption $\alpha c_{1}$ with the least amount of resources for any given level of $c_{1}$. Consequently, she reaches the highest feasible level of $c_{1}$.

With respect to the desirability of a PAYGO asset, it follows that the individual will benefit from such an asset if and only if it exhibits the highest minimum return, i.e. if and only if $\underline{z}>\underline{x}$. Remember, however, that this result depends on the hypothesis that only the first two goals of preferences (1) are relevant for $w \leq w^{\text {crit }}$. The validity of this assumption has still to be checked. If the individual invests only in the assets with the highest minimum return, it follows from (2) that $c_{1}=\frac{\max [\underline{x}, \underline{z}]}{\alpha+\max [\underline{x}, \underline{z}]} w$. (Use $\tilde{c}_{2}^{\min }=$ $\left.\left(w-c_{1}\right) \cdot \max [\underline{x}, \underline{z}].\right)$ From $w \leq w^{\text {crit }}$ it follows that $c_{1} \leq \bar{c}$. This confirms that for $w \leq w^{\text {crit }}$, behavior is indeed determined by program (2). This allows stating the following result.

Proposition 1 Assume $w \leq \frac{\alpha+\max [\underline{x}, \underline{z}]}{\max [\underline{x}, \underline{z}]} \bar{c} \equiv w^{\text {crit }}$. Then $c_{1} \leq \bar{c}$, and individuals invest only in the asset with the highest minimum return. The PAYGO asset is beneficial if and only if $\underline{z}>\underline{x}$.

Proof. See the text above.

Proposition 1 implies that individuals with an income below $w^{\text {crit }}$ are best off when having all their private savings replaced by a PAYGO system, whenever the PAYGO system offers the highest minimum returns in the economy. It is the loss aversion property of preferences (1) that implies this strong result. If individuals cannot freely invest in the PAYGO asset, then they will also invest in bonds whenever the coverage trough a PAYGO system is lower than optimal. In contrast, they will never invest in stocks. Thus, the model is consistent with the empirical fact that low-income earners do not hold equities. Remember from the introduction that this is not the case for existing loss aversion models, incorporating this phenomenon into an expected utility framework. ${ }^{14}$

\footnotetext{
${ }^{14}$ See Binswanger (2005) for a discussion.
} 
I turn next to the case of high incomes where all three preference goals are relevant. It follows from the above analysis that this is the case when $w>w^{\text {crit }}$. Let us start with a portfolio for which $b>0$ and the individual is constrained to choose $p=0$. (It follows from Binswanger (2005) that under the latter constraint $b>0$ holds whenever $\gamma \geq \overline{\bar{\gamma}}$, or $\gamma<\overline{\bar{\gamma}}$ and $w<\overline{\bar{w}}$, where $\overline{\bar{\gamma}} \equiv \frac{\underline{y} \Omega}{\alpha(\underline{x}-\underline{y}) E \tilde{y}}, \overline{\bar{w}} \equiv \frac{(\alpha+\underline{y}) \Omega}{\underline{y} \Omega-\alpha \gamma(\underline{x}-\underline{y}) E \tilde{y}} \bar{c}$ and $\Omega \equiv(\alpha+\underline{x}) E \tilde{y}-(\alpha+\underline{y}) E \tilde{x}$. For very low values of $\gamma$, combined with high incomes, the individual might only invest in stocks.) Consider now the conditions under which the individual will be better off when given the opportunity to choose $p>0$. This will be the case if and only if there exists a portfolio reallocation $(\Delta b, \Delta s, \Delta p)$ modifying the initial portfolio such that

$$
\begin{aligned}
& \Delta p>0, \Delta b<0, \\
& \Delta c_{1}=\Delta b+\Delta s+\Delta p=0, \\
& \Delta \tilde{c}_{2}^{\text {min }}=\Delta b \underline{x}+\Delta s \underline{y}+\Delta p \underline{z}=0, \\
& \Delta E \tilde{c}_{2}=\Delta b E \tilde{x}+\Delta s E \tilde{y}+\Delta p E \tilde{z}>0 .
\end{aligned}
$$

To see this, note that the reallocation will indeed increase the value of the third goal in (1) while leaving the value of the first and second goal unaffected. To see the converse, note that the only other possibility to increase the third goal is to increase either only $c_{1}$, or $c_{1}$ and $E \tilde{c}_{2}$ together. By continuity this is feasible whenever the reallocation (3) is feasible. Furthermore, the second to forth line in (3) and Assumption 1 imply $\operatorname{sign} \Delta b \neq \operatorname{sign} \Delta p$. Note that the reallocation (3) is feasible only when $b>0$ initially. ${ }^{15}$

Whenever there exists a reallocation fulfilling (3), then optimal bond holdings are zero. This follows from the fact that this type of reallocation is feasible for any value of $b>0$. Noting this and solving the system (3), we get the following result.

Proposition 2 Assume $w>w^{\text {crit }}$. Furthermore, assume $\gamma \geq \overline{\bar{\gamma}}$, or $\gamma<\overline{\bar{\gamma}}$ and $w<\overline{\bar{w}}$, where $\overline{\bar{\gamma}} \equiv \frac{\underline{y} \Omega}{\alpha(\underline{x}-\underline{y}) E \tilde{y}}, \overline{\bar{w}} \equiv \frac{(\alpha+\underline{y}) \Omega}{\underline{y} \Omega-\alpha \gamma(\underline{x}-\underline{y}) E \tilde{y}} \bar{c}$ and $\Omega \equiv(\alpha+\underline{x}) E \tilde{y}-(\alpha+\underline{y}) E \tilde{x}$. Then

i. $b>0$ in the absence of a PAYGO asset,

\footnotetext{
${ }^{15}$ See Binswanger (2004) for a fully-fledged analysis of the investment problem with three risky assets.
} 
ii. the PAYGO asset is beneficial if and only if

$$
\underline{z}(E \tilde{y}-E \tilde{x})+(\underline{x}-\underline{y}) E \tilde{z}>\underline{x} E \tilde{y}-\underline{y} E \tilde{x},
$$

iii. $b=0$ if (4) holds.

Proof. See the text above. To obtain condition (4) solve (3) using the second and third line to express $\Delta b$ and $\Delta s$ in $\Delta p$. Insert the resulting expressions in the forth line in (3) and remember that we require $\Delta p>0$.

Remember that $\gamma \geq \overline{\bar{\gamma}}$, or $\gamma<\overline{\bar{\gamma}}$ and $w<\overline{\bar{w}}$ simply assure that $b>0$ in the absence of the PAYGO asset. (It can be checked that $w^{\text {crit }}<\overline{\bar{w}}$.) Condition (4) provides an amazingly simple criterion for the desirability of a PAYGO system. A particularly nice feature of this condition is that it is straightforward to evaluate empirically, which will be done in the next subsection. Note that evaluation of (4) does not even require information about preference parameters. Not surprisingly, this condition requires that $\underline{z}$ or $E \tilde{z}$ must not be too low. Specifically, it rules out $\underline{z}<\underline{x}, E \tilde{z}<E \tilde{x}$, i.e. that the PAYGO system is dominated by bonds. The simplicity of condition (4) is particularly welcome when noting that no condition of comparable transparency can be expected to be obtained for expected utility models. This conclusion is inferred from the analysis of Eeckhoudt and Gollier (2001), and Gollier (2001, Ch. 10). They show that even the introduction of only a second risky asset, in addition to another already available risky asset, is a very intricate issue. In light of their results, the case of three risky assets, which is relevant here, appears to be very difficult to characterize under expected utility preferences.

The result that optimal bond holdings are zero whenever (4) holds may be surprising at first sight. This is explained by the fact that pure loss aversion is the only driving force of risk aversion in the preference specification (1). This excludes a diversification motive for portfolio allocation. However, abstracting from diversification allows exploring the implications of loss aversion, a first-order issue for a behaviorally oriented analysis of risk management, in a most transparent way. Section 5 will present an enriched version of the lexicographic model that accounts for a more general aversion to the dispersion of old-age consumption. 
Before turning to an empirical evaluation of condition (4) and the calibration of optimal pension plans, let us complete the theoretical analysis by considering the values of $\gamma$ and $w$ that are not covered by Proposition 1 and 2 . For these, the habit level $\alpha c_{1}$ and thus satiation of the first goal in (1) can be achieved merely by stock investments. Thus, a PAYGO asset will not have any value.

\section{Calibration of Optimal Pension Plans}

Let us start the numerical analysis of optimal pension plans by evaluating condition (4). This requires only information about expected values and minimum realizations of the growth rate of aggregate wage income and bond and stock returns. As indicated in Section 2, expected values amount to 77,69 and 659 percent for a time horizon of 32 years, respectively. For the specification of minimum returns I use fifth percentiles. They corresponds most closely to the idea of return levels that are exceeded with a high probability while not representing excessively conservative specifications of minimum returns. According to Section 2, minimum returns are thus 2, minus 8 and minus 31 percent for the PAYGO system, bonds and stocks, respectively. In light of these figures, the PAYGO system dominates bonds with respect to both, expected values and minimum returns, implying that (4) holds. ${ }^{16}$

In the following, I discuss first the numerical specification of preference parameters. Then I indicate the formulas for optimal investment/pension plans corresponding to the respective parameter ranges. Finally, the formulas are used to obtain a calibration of optimal plans. There are three preference parameters to be specified numerically: $\alpha, \gamma$, $\bar{c}$. Concerning $\alpha$, let us first find a value that seems appropriate when comparing average annual consumption during retirement to average annual consumption during working life. Following Binswanger (2005), I set the fraction of annual active period consumption that individuals do not allow to be undercut by annual retirement consumption equal to the average US Social Security replacement rate. The latter amounts to .4 (see Munnell,

\footnotetext{
${ }^{16}$ Remember from Figure 1 that this conclusion is robust to changes in percentiles.
} 
2004). This value has to be adjusted to take into account that the retirement period typically lasts for fewer years than working life. This happens by multiplying the Social Security replacement rate by the ratio of the length of retirement to the length of working life. ${ }^{17}$ The resulting numerical value of $\alpha$ amounts to .20 .

Concerning $\gamma$, inspection of (1) shows that it just represents the inverse of a standard discount factor. Take logs of the third goal to see this. In the life-cycle literature a usual specification of the annual discount factor is .96 (see e.g. Campbell et al., 2001). Raising this number to the power of 32 (the model's time horizon) and taking the inverse yields a raw estimate of $\gamma$. I multiply this raw specification by the ratio of the length of retirement to the length of active life, again to account for the fact that the retirement period is typically shorter than working age. This yields a numerical specification for $\gamma$ of 7.5 . The final parameter $\bar{c}$ is set to 25,000 year 2001 US dollars. It is shown in Binswanger (2005) that this value does a particularly good job in capturing the empirical income threshold separating households which invest in stocks from households that do not. Assumption 4 summarizes the numerical model specification.

Assumption 4 (i) $\alpha=.20, \bar{c}=25,000, \gamma=7.5$, (ii) $E \tilde{x}=1.69, \underline{x}=0.92, E \tilde{y}=6.59$, $\underline{y}=0.69, E \tilde{z}=1.77, \underline{z}=1.02$.

For the case where $\underline{z}>\underline{x}$ and (4) holds, Proposition 1 and 2, together with the last paragraph in the last subsection, imply that $b=0$ for all income levels. As a result, under Assumption 4 optimal plans coincide with the plans that are chosen when only stocks and the PAYGO asset are available. The formulas for optimal investments corresponding to this two-asset problem can be taken from Binswanger (2005). For the parameter range corresponding to Assumption 4 they are as follows.

Proposition 3 If $\underline{z}>\underline{x}$ and (4) holds, then $b=0$ for all income levels. Moreover, under

\footnotetext{
${ }^{17}$ See footnote 9 for the assumptions regarding the length of working age and retirement. The specification of $\alpha$ by means of average life-expectancies is only valid under the availability of annuities. Otherwise, one would have to account for the risk of outliving one's assets such that a higher value of $\alpha$ would be appropriate.
} 
Assumption 4 we have

$$
\begin{aligned}
& p= \begin{cases}\frac{\alpha}{\alpha+\underline{z}} w & \text { if } w \leq \hat{w} \\
\frac{1}{(1+\gamma)(\underline{z}-\underline{y}) \hat{\Omega}}\{[\alpha \gamma(\underline{z}-\underline{y}) E \tilde{y}-\underline{y} \hat{\Omega}] w+(\alpha+\underline{y}) \hat{\Omega} \bar{c}\} & \text { if } \hat{w}<w<\hat{\hat{w}} \\
0 & \text { if } w \geq \hat{\hat{w}}\end{cases} \\
& s= \begin{cases}0 & \text { if } w \leq \hat{w} \\
\frac{1}{(1+\gamma)(\underline{z}-\underline{y}) \hat{\Omega}}\{[\underline{z} \hat{\Omega}-\alpha \gamma(\underline{z}-\underline{y}) E \tilde{z}] w-(\alpha+\underline{z}) \hat{\Omega} \bar{c}\} & \text { if } \hat{w}<w<\hat{\hat{w}} \\
\frac{\alpha}{\alpha+\underline{y}} w & \text { if } w \geq \hat{\hat{w}}\end{cases}
\end{aligned}
$$

where $\hat{w} \equiv \frac{(\alpha+\underline{z}) \hat{\Omega}}{\underline{z} \hat{\Omega}-\alpha \gamma(\underline{z}-\underline{y}) E \tilde{z}} \bar{c}, \hat{\hat{w}} \equiv \frac{(\alpha+\underline{y}) \hat{\Omega}}{\underline{y} \hat{\Omega}-\alpha \gamma(\underline{z}-\underline{y}) E \tilde{y}} \bar{c}$ and $\hat{\Omega} \equiv(\alpha+\underline{z}) E \tilde{y}-(\alpha+\underline{y}) E \tilde{z}$.

Proof. See the text above and Binswanger (2005).

The formulas in Proposition 3 can be used to calibrate optimal pension/investment plans. Figure 2 shows optimal expenditure shares for PAYGO and stock investments, i.e. $\frac{p}{w}$ and $\frac{s}{w}$, as well as their sum. The red bold solid line corresponds to PAYGO investments. The dotted blue line represents equity investments. The thin solid azure line represents the sum of both. Remember that optimal bond investments are zero. Remember also that a social planner would set contribution rates of a mandatory PAYGO system equal to optimal PAYGO expenditure shares. If the latter differ between different incomes then it would be necessary to implement separate PAYGO systems for different income classes.

For income levels below 34,000 year 2001 dollars, households are best off by having all their savings substituted by a PAYGO system. ${ }^{18}$ The optimal PAYGO contribution rate amounts to 16 percent. According to the income quintile estimates of the US Census Bureau for 2001, this concerns the two lowest income quintiles. ${ }^{19}$ Optimal equity savings are zero. For income levels between 34,000 and 53,000, corresponding to the third income quintile, the PAYGO rate drops from 16 to 8 percent, while equity savings increase from zero to 11 percent. This implies that the equity share, defined as equity savings relative to

\footnotetext{
${ }^{18}$ Income levels should be understood as annual permanent incomes.

${ }^{19}$ See http:/www.census.gov/hhes/income/histinc/h01ar.html.
} 


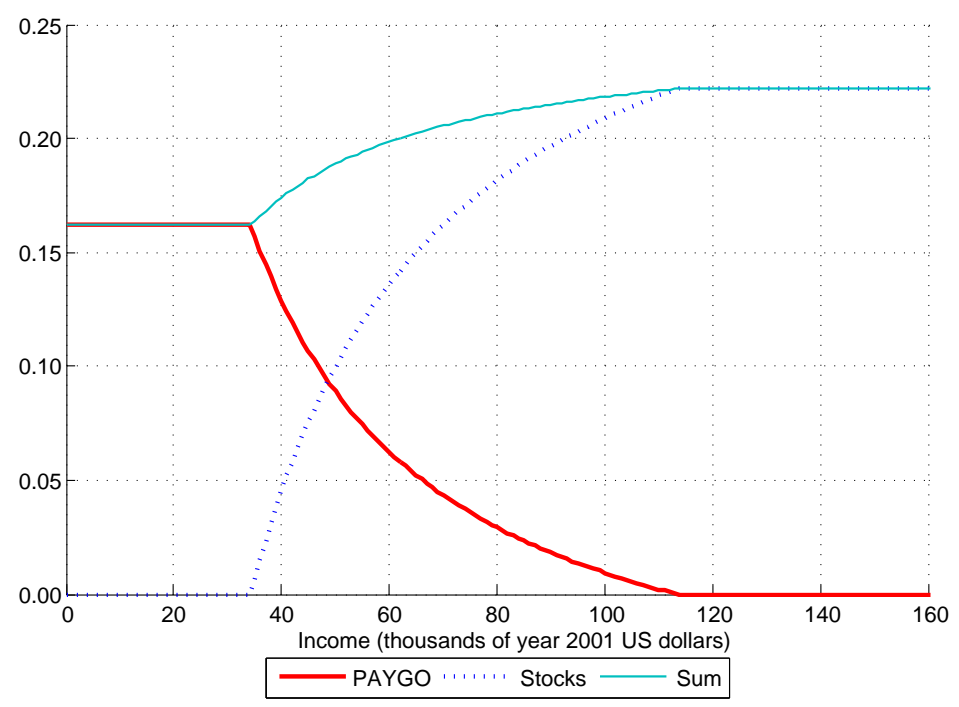

Figure 2. Optimal investment rates under lexicographic loss aversion, baseline case.

total savings including PAYGO savings, increases from 0 to 58 percent. For the upper limit of the forth quintile, amounting to 83,000, the PAYGO rate equals 3 percent and equity savings amount to about 19 percent, implying an equity share of 88 percent. PAYGO rates approach zero at an income of 114,000 where equity savings approach 22 percent. ${ }^{20}$

Total saving rates increase from 16 percent to 22 percent over the entire range of incomes. In contrast, empirical estimates for saving rates, including Social Security savings, range from 7 to 14 percent for the two lowest income quintiles. For the fifth quintile they range from 24 to 34 percent. $^{21}$ Thus, the total saving rates in Figure 2 exceed empirical saving rates for low incomes while they fall short of saving rates of the rich. However, it

\footnotetext{
${ }^{20}$ Compared to empirical observations, the equity shares derived here are higher for the three upper income quintiles (see Section 6 and Table 2). In order to match empirical equity shares, a higher $\alpha$ would be needed. Remember that in this paper $\alpha$ has been set proportional to the average length of retirement. In Binswanger (2005) it is shown that empirical equity shares are matched almost perfectly when $\alpha$ is set proportional to the $99^{\text {th }}$ percentile of the length of retirement. This conservative specification accounts for the risk of outliving one's assets. However, in the context of pensions, where investment payouts are annuitized, determining $\alpha$ according to the average length of retirement seems more appropriate. See also footnote 17 .

${ }^{21}$ See Dynan et al. (2004).
} 
should be noted that empirical saving rates are low for the bottom quintiles partly because of redistributive elements within Social Security and other welfare programs, which have been neglected by the analysis here.

To get a further feeling with regard to the sensibility of the saving rates in Figure 2, consider the probability that annual old-age consumption falls short of 40 percent of annual working-age consumption. Minimum returns have been identified with the returns corresponding to the fifth percentile. For optimal choices we have $\tilde{c}_{2}^{\min }=\alpha c_{1}$, where $\alpha$ has been set such that it corresponds to an annual value of 40 percent. Thus, annual old-age consumption is lower than 40 percent of annual working-age consumption with a probability of about 5 percent for the saving rates shown in Figure 2. As a consequence, if saving rates are smaller than indicated in the figure, annual old-consumption falls short of 40 percent of annual working-age consumption with a probability that is higher than 5 percent. Since a replacement rate of 40 percent is rather low, the downside risk exposure of old-age income then becomes substantial.

\section{Optimal Pension Plans under Generalized Risk Aver- sion}

This section presents a calibration of optimal pension plans accounting for a more general pattern of risk aversion. In particular, preferences are augmented by an aversion to the dispersion of old-age consumption, in addition to loss aversion. Specifically, preferences are given by

$$
\Pi^{\prime}=\left\{I\left(\tilde{c}_{2}^{\min } \geq \alpha c_{1}, \sigma\left(\tilde{c}_{2}\right) \leq \theta\left(E \tilde{c}_{2}\right) E \tilde{c}_{2}\right), \min \left[c_{1}, \bar{c}\right], E \tilde{c}_{2}\left(c_{1}-\bar{c}\right)^{\gamma}\right\}
$$

where $\sigma\left(\tilde{c}_{2}\right)$ denotes the standard deviation of $\tilde{c}_{2}$ and $\theta>0$ represents a parameter that might depend on $E \tilde{c}_{2}$. Thus, achieving the first goal now requires not only assuring habit consumption during old-age, but also that the dispersion of old-age consumption, measured by its standard deviation, must not exceed a certain fraction of expected old-age 
consumption.

Preferences (5) represent the most direct extension of the baseline version (1) of lexicographic preferences. However, this specification suffers from the fact that it may not be feasible to achieve the inequalities $\tilde{c}_{2}^{\text {min }} \geq \alpha c_{1}$ and $\sigma\left(\tilde{c}_{2}\right) \leq \theta E \tilde{c}_{2}$ simultaneously for certain values of $\alpha$ and $\theta$. This problem is addressed by assuming that behavior is determined by a continuous approximation of (5). In particular, I assume that individuals maximize the function

$$
c_{1}-\lambda \max \left(0, \alpha c_{1}-\tilde{c}_{2}^{\min }\right)^{2}-\lambda \max \left(0, \sigma\left(E \tilde{c}_{2}\right)-\theta E \tilde{c}_{2}\right)^{2}
$$

whenever the resulting value of $c_{1}$ falls short of $\bar{c}$, and

$$
E \tilde{c}_{2}\left(c_{1}-\bar{c}\right)^{\gamma}-\lambda \max \left(0, \alpha c_{1}-\tilde{c}_{2}^{\min }\right)^{2}-\lambda \max \left(0, \sigma\left(E \tilde{c}_{2}\right)-\theta E \tilde{c}_{2}\right)^{2}
$$

otherwise. $\lambda$ is a penalty parameter representing a large but finite number. ${ }^{22}$

Note that for these objective functions the rate of risk aversion is no longer infinite as for preferences (1) or (5). Thus, individuals are ready to trade off violations of the inequalities $\tilde{c}_{2}^{\min } \geq \alpha c_{1}$ and $\sigma\left(\tilde{c}_{2}\right) \leq \theta E \tilde{c}_{2}$. Because of this, and due to the more general specification of risk aversion, the extended model (6) and (7) is certainly more appealing from a normative point of view than the preference model (1). Therefore, policy implications that are inferred from the analysis of this paper should be mainly based on the results developed in this section rather than the previous one. Nevertheless, the behavioral foundations of preferences (1), i.e. loss aversion with respect to a habit level of consumption and with respect to a normal standard of living, are entirely preserved. The comparison of the prescriptions of the model (6) and (7) with the prescriptions of the baseline preference model discussed in the last section allows a clear-cut identification of which elements of an optimal pension plan are due to pure loss aversion and which elements are explained by a diversification motive.

The income expansion paths for PAYGO, bond and equity saving rates are derived numerically, using grid search. The values of $\theta$ are specified such that a good fit to

\footnotetext{
${ }^{22}$ While the functions (6) and (7) resemble mean-variance utility functions, they have the advantage that they do not imply decreasing income expansion paths for equity shares.
} 
Table 1: Correlation matrix of return rates.

\begin{tabular}{|l||c|c|c|}
\hline & PAYGO & Bonds & Stocks \\
\hline \hline PAYGO & 1 & -0.26 & 0.29 \\
\hline Bonds & -0.26 & 1 & 0.12 \\
\hline Stocks & 0.29 & 0.12 & 1 \\
\hline
\end{tabular}

empirical equity shares is obtained for the "private" investment problem where there are only stocks and bonds available. This leads to values of $\theta$ that are constant at .13 in the domain where behavior is determined by (6). In the domain where behavior is determined by (7), $\theta$ starts to increase smoothly up to $.41 .{ }^{23}$ Expected and minimum return rates are again specified according to Assumption 4. For the objective functions (6) and (7) optimal plans depend on correlations between different return rates. The correlation matrix for the case where bond, stock and PAYGO returns are jointly lognormal is shown in Table $1 .{ }^{24}$

The results are shown in Figure 3. The bold solid red line represents the PAYGO rate, the green dashed and dotted blue line correspond to bonds and stocks, respectively. The thin solid azure line shows the sum of all three investment rates. For incomes up to 40,000 the PAYGO rate equals 8 percent, bond investments amount to 7 percent and stock investments to one percent. Comparing the left parts of Figure 3 and Figure 2 shows that dispersion aversion makes the case for positive bond investments. Specifically, for lower incomes about half of optimal PAYGO investments under baseline preferences are substituted by bonds due to the negative correlation between bond and PAYGO returns (see Table 1). In addition, in contrast to the baseline case, it is optimal to invest even

\footnotetext{
${ }^{23}$ Specifically, values for $\theta$ are derived using an "indirect utility" approach. Four values of $\theta$ are specified such that median equity shares from the Survey of Consumer Finances (SCF) 2001 are fitted for median incomes for the four upper SCF income quintiles, subject to the constraint that $\theta \geq 0.01$. For these four income levels, behavior is determined by the objective function (7). For the median income of the first $\mathrm{SCF}$ income quintile, for which behavior is determined by (6), $\theta$ is set to the same value as for the second quintile. For intermediate incomes, $\theta$ is obtained by interpolation.

${ }^{24}$ The derivation of the joint distribution is described in footnote 9.
} 


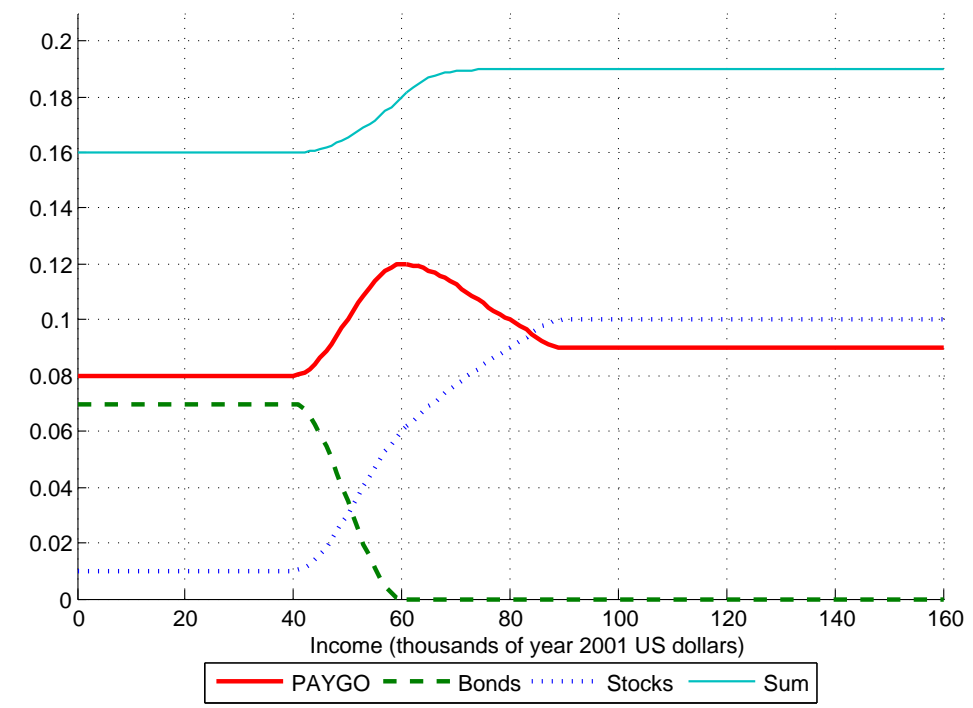

Figure 3. Optimal investment rates under lexicographic loss aversion, generalized risk aversion.

a very small amount in equities at low incomes. However, the two most basic insights of Figure 2 are preserved. First, optimal PAYGO rates are substantial. Second, optimal equity shares are very low.

For incomes exceeding 40,000 the marginal propensity to save increases because behavior is now determined by maximization of (7). Additionally, the marginal propensity to risky saving raises as $\theta$ is now increasing. The first-order effect of increased risk-taking is an increase in the equity savings rate. Associated with this is a substitution of bonds by PAYGO savings. Note that the latter are higher for all income levels exceeding 40,000 than for incomes below this level. The reason is that under loss aversion, PAYGO investments are better complements to equities than bonds, as they offer a better protection against the downside risks associated with equity investments. ${ }^{25}$ Specifically, it turns out that bonds do not make any valuable contribution to the reduction of old-age income dispersion above 60,000 . Between 40,000 and 60,000 the propensity to risky savings takes intermediate values. As a result, PAYGO investments increase with higher equity investments to compensate the sharp drop in bond investments and also to account for an

\footnotetext{
${ }^{25}$ See also Section 6.
} 
increased propensity to total savings. For incomes exceeding 60,000, the propensity to risky savings is sufficiently high such that the PAYGO rate decreases to 9 percent whereas equity savings increase to 10 percent.

Total saving rates increase from 16 to 19 percent and are thus somewhat lower than in Figure 2. Equity shares increase from 6 percent for low incomes to 53 percent for high incomes. Thus, their variation is more moderate than for the baseline version of the model. However, it is still considerable. Overall, the two most important differences between Figure 3 and Figure 2 are the following. First, relatively high PAYGO rates remain desirable for high incomes under generalized risk aversion. Second, bond investment rates are substantial for low incomes. In contrast, bond investments coincide with the baseline version of the model for higher incomes where they are zero.

\section{Comparison to HARA Preferences}

In order to highlight the specific implications of lexicographic loss aversion preferences for optimal pension design, it is useful to make the comparison to optimal plans under expected utility preferences. As discussed in the introduction, constant relative risk aversion (CRRA) preferences do not leave any role for income heterogeneity with respect to investment rates. As a result, the comparison between optimal pension plans under CRRA and under lexicographic preferences is not of particular interest. Therefore, I choose a relatively general HARA specification as a benchmark to which the prescriptions of the lexicographic model should be compared.

Specifically, I consider the HARA specification

$$
U\left(c_{1}, \tilde{c}_{2}\right)=\frac{1}{1-\eta}\left(c_{1}-\overline{\bar{c}}_{1}\right)^{1-\eta}+\frac{\beta}{1-\eta} E\left(\tilde{c}_{2}-\overline{\bar{c}}_{2}\right)^{1-\eta} .
$$

The parameters of this utility function are $\eta$, governing relative risk aversion, $\overline{\bar{c}}_{1}>0$,

$\overline{\bar{c}}_{2}>0$, representing age-specific subsistence levels of consumption, and $\beta$, representing the time discount factor. $E$ denotes the mathematical expectation operator. The utility function (8) is well behaved only for the case where $c_{1}>\overline{\bar{c}}_{1}, \tilde{c}_{2}>\overline{\bar{c}}_{2}$. Note that relative 
risk aversion is equal to $\eta$ in the limit case where consumption equals infinity. For finite consumption values relative risk aversion exceeds $\eta$. Note further that the limit case where $\eta=1$ corresponds to the usual log version of Stone-Geary preferences.

For the derivation of optimal pension plans, the return distributions are truncated below at the fifth percentile in order to avoid that saving rates become excessively high due to the fact that feasibility of subsistence consumptions has to be assured with probability one. Additionally, return distributions are truncated at the top in such a way that expected values of the truncated distributions correspond to historical geometric means.

Figures $4 \mathrm{a}$ to $4 \mathrm{~d}$ present optimal pension plans for four different parameter constellations. In all figures, the bold solid red line represents the PAYGO rate, the green dashed and dotted blue line correspond to bonds and stocks, respectively. The thin solid azure line shows the sum of all three investment rates. Note that for incomes at the left end of the diagrams optimal choices are not defined. The reason is that income is not sufficient to cover subsistence consumptions. Figure 4a shows optimal plans for a baseline specification where parameters are chosen strictly on an ex-ante basis. In particular, $\overline{\bar{c}}_{1}$ and $\overline{\bar{c}}_{2}$ are set to age-specific poverty threshold levels for the US, amounting to 14,100 and 10,700 for working-age and retirement, respectively. ${ }^{26}$ Moreover, $\eta$ is set equal to 3 and $\beta$ equal to $.96^{32}$ times the ratio of the length of retirement to the length of working age, to account for the fact that retirement typically last for fewer years than working age. ${ }^{27}$ The most disturbing feature of the outcome from this specification is that total saving rates are unreasonably high and decreasing in income. Empirical saving rates range from 6 to 14 percent for the two lowest income quintiles. Estimates for the top quintile range from

\footnotetext{
${ }^{26}$ Source: US Census Bureau. The figures represent poverty thresholds for a weighted average of threeperson households for working age, and a weighed average of two-person households with age greater or equal to 65 years for retirement, respectively.

${ }^{27}$ Remember that 32 equals the length of the investment time-horizon. See footnote 9 for more details. An annual discount factor of .96 corresponds to a usual assumption in the life-cycle literature. Moreover, relative risk aversion is often set between 4 and 6 . A value for $\eta$ of 3 has been chosen as implying values of relative risk aversion that come close to this range. Remember that for preferences (8) relative risk aversion exceeds $\eta$ for finite consumption levels.
} 


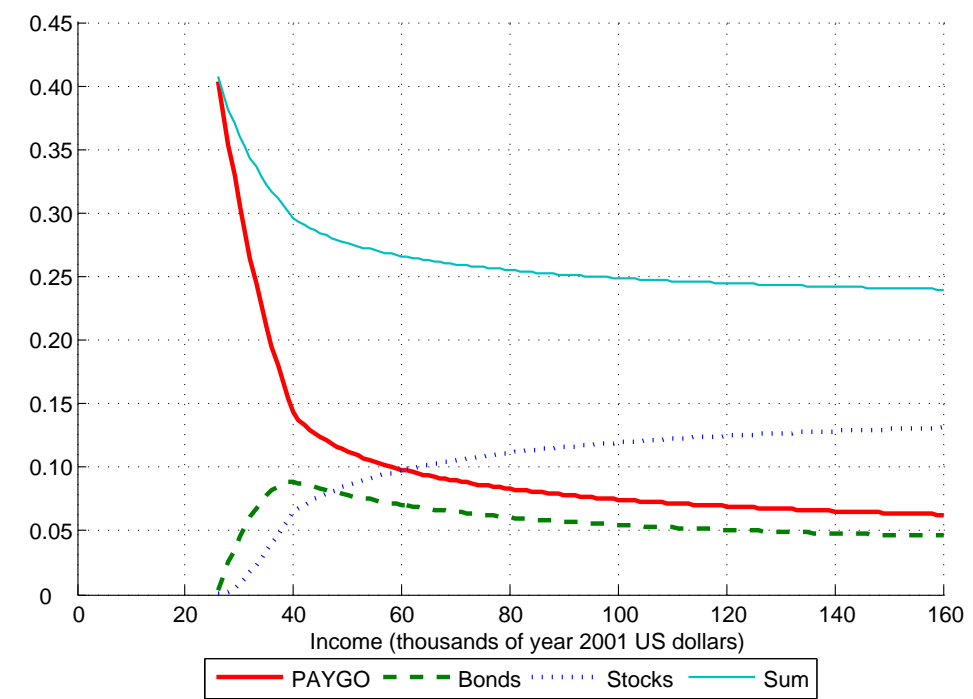

Figure 4a. Optimal investment rates under HARA preferences, $\eta=3$, subsistence consumptions according to poverty thresholds.

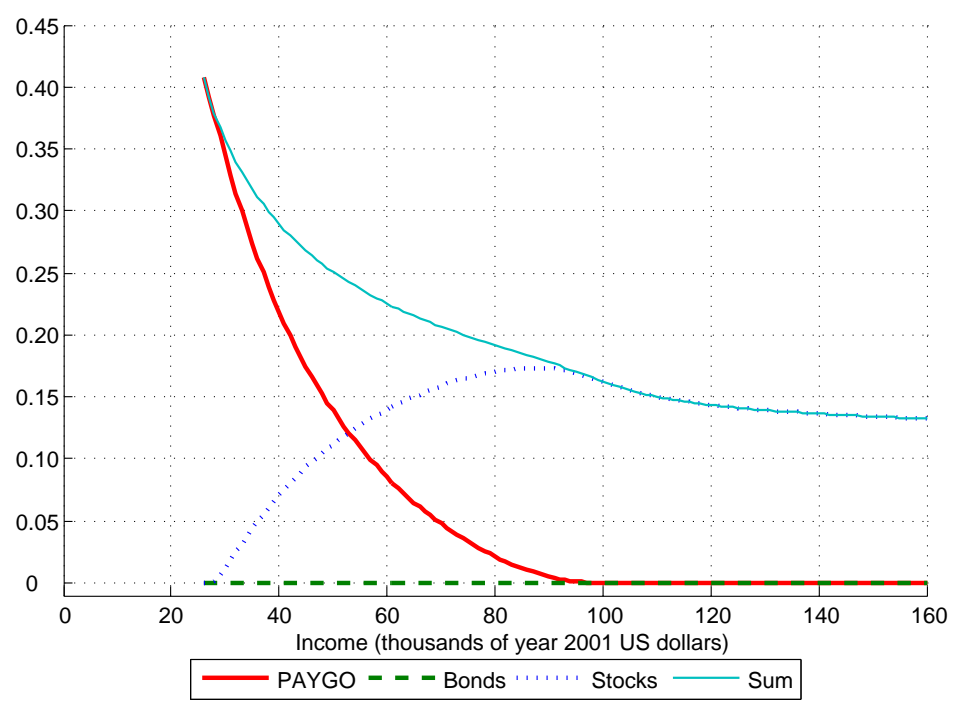

Figure 4b. Optimal investment rates under StoneGeary preferences $(\eta=1)$, subsistence consumptions according to poverty thresholds. 


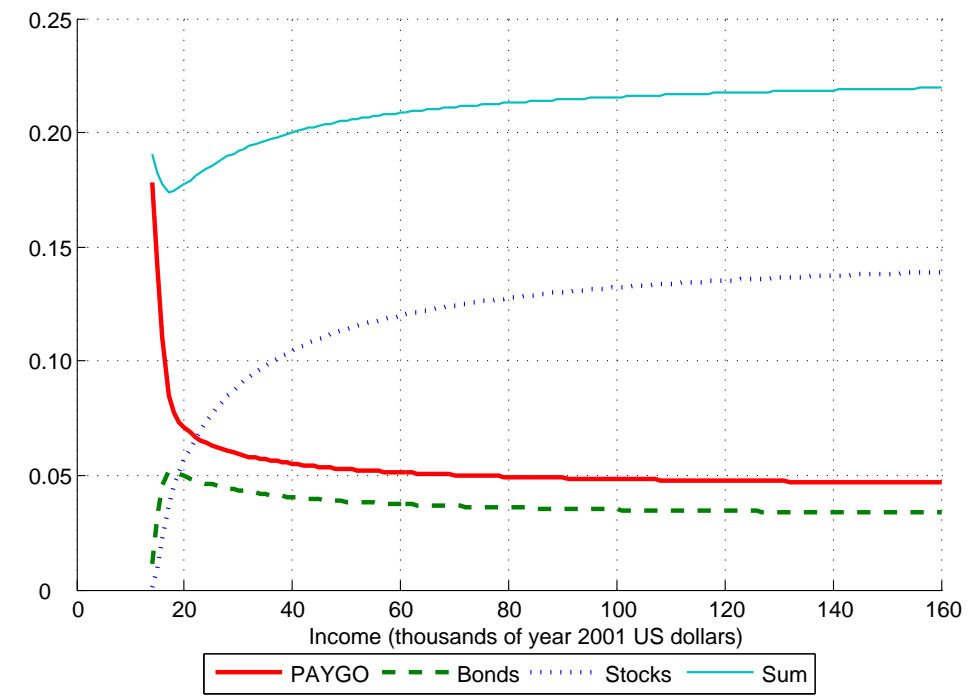

Figure 4c. Optimal investment rates under HARA preferences, $\eta=3$, low subsistence consumption ratio.

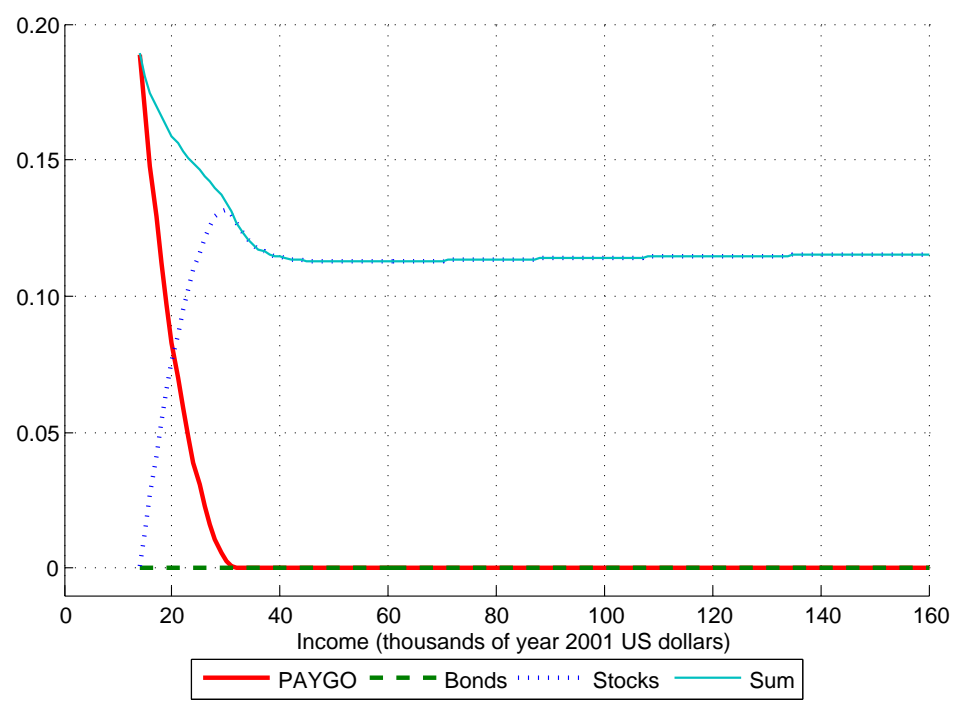

Figure 4d. Optimal investment rates under StoneGeary preferences $(\eta=1)$, low subsistence consumption ratio. 
24 to 34 percent. $^{28}$ In light of this, the outcome of the baseline specification can hardly be accepted as a policy guideline.

It might seem that the problem of high and decreasing saving rates is alleviated when $\eta$ is set to a lower value. Figure $4 \mathrm{~b}$ shows the outcome for the limit case where $\eta=1$ (and all other parameters are set equal to the baseline values). This corresponds to the usual log-version of Stone-Geary preferences. Unfortunately, for this specification total saving rates are even less consistent with empirical observations. It turns out that decreasing saving rates are avoided only if the ratio $\overline{\bar{c}}_{2} / \overline{\bar{c}}_{1}$ is sharply reduced. Figure $4 \mathrm{c}$ shows optimal plans when $\overline{\bar{c}}_{1}$ is reduced by one quarter and $\overline{\bar{c}}_{2}$ by three quarters compared to age-specific poverty thresholds. All other parameters are again set equal to the baseline values. Finally, Figure $4 \mathrm{~d}$ shows a calibration for reduced subsistence levels when $\eta=1 .^{29}$

In Figure 4d equity shares approach one already at relatively low incomes. Because of this extreme outcome, the policy implications of this specification seem again unacceptable. Thus, there are only the plans shown in Figure 4c that deserve serious attention. For these, PAYGO rates are high but rapidly decreasing for incomes between 14,000 and 18,000. In this region, the PAYGO system is particularly valuable because it exhibits the highest minimum return and thus assures the feasibility of old-age subsistence consumption. This corresponds to the logic of the lexicographic model where a PAYGO system allows to assure the habit level $\alpha c_{1}$ in the most efficient way. For higher incomes, assuring old-age subsistence consumption ceases to be a driving motive of portfolio choice under HARA preferences. Thus, PAYGO investments are rather low. In contrast, equity savings increase quite quickly.

The key differences between optimal plans under lexicographic and under HARA preferences, according to the specification underlying Figure 4c, are highlighted in Table 2 and 3. Table 2 presents equity investments as a share of total savings for mean incomes of each income quintile, according to the estimates of the US Census Bureau. ${ }^{30}$ These

\footnotetext{
${ }^{28}$ See the estimates for saving rates including pensions and social security savings in Dynan et al. (2004).

${ }^{29}$ Calibrations for alternative parameter specifications are available upon request.

${ }^{30}$ See http://www.census.gov/hhes/income/histinc/h03ar.html.
} 
Table 2: Equity investments as a share of total savings.

\begin{tabular}{|l|c||c|c|c|c|}
\hline Quintile & Income & LEX baseline & LEX generalized & HARA & Empirical \\
\hline \hline First & 10,136 & 0 & 0.06 & NaN & 0 \\
\hline Second & 25,468 & 0 & 0.06 & 0.41 & 0 \\
\hline Third & 42,629 & 0.36 & 0.08 & 0.53 & 0.07 \\
\hline Forth & 66,839 & 0.76 & 0.38 & 0.58 & 0.37 \\
\hline Fifth & 145,970 & 1 & 0.53 & 0.63 & 0.54 \\
\hline
\end{tabular}

mean quintile incomes are reported in the second column. The third and fourth column present equity shares as prescribed by the baseline and generalized lexicographic model, respectively. The fifth column shows equity shares that correspond to the HARA case. Finally, the last column presents empirical estimates of equity shares from the Survey of Consumer Finances 2001. It reports median equity shares, including equities hold through mutual funds and private pensions, for each income quintile. (Observations with age higher than 65 are dropped from the sample.)

Table 2 shows that under lexicographic preferences equity shares are much lower for the second and third quintile than in the HARA case. In particular, prescribed equity shares correspond more closely to empirical observations. Note that optimal choices are not defined under HARA preferences for the first quintile. For the two top quintiles both, the HARA and the generalized lexicographic model, track empirical equity shares closely while equiy shares are much higher for the baseline version of the lexicographic model. This is mainly due to the fact that $\alpha$ has been specified proportionally to the average length of retirement age and there is no diversification motive. ${ }^{31}$ Table 3 presents PAYGO investments as a share of total savings. PAYGO shares are almost uniformly higher under both lexicographic preferences. Moreover, the quantitative difference is substantial for most quintiles. This is explained by the fact that under loss aversion the favorable downside risk protection offered by the PAYGO system is particularly valuable.

\footnotetext{
${ }^{31}$ See footnote 17 and 20.
} 
Table 3: PAYGO investments as a share of total savings.

\begin{tabular}{|l|c||c|c|c|}
\hline Quintile & Income & LEX baseline & LEX generalized & HARA \\
\hline \hline First & 10,136 & 1 & 0.50 & NaN \\
\hline Second & 25,468 & 1 & 0.50 & 0.34 \\
\hline Third & 42,629 & 0.64 & 0.51 & 0.27 \\
\hline Forth & 66,839 & 0.24 & 0.62 & 0.24 \\
\hline Fifth & 145,970 & 0 & 0.47 & 0.21 \\
\hline
\end{tabular}

\section{Conclusion}

Poterba et al. (2003, p. 26) express the worry that "... choices predicted by the CRRA function may be a poor guide to actual behavior when the distribution of wealth outcomes includes values near zero." This paper has studied old-age provision and pension design under lexicographic loss aversion preferences, which are consistent with the idea that individuals are particularly averse to low investment outcomes. Calibrations of optimal pension plans have been provided for two different versions of the lexicographic model. A baseline version focuses merely on the implications of loss aversion, abstracting from diversification issues. A second variant accounts for a more general pattern of risk aversion. From a normative point of view, more weight should be put on the prescriptions of the latter version of the model.

According to the generalized risk aversion variant of the model, optimal contribution rates for a PAYGO system generally amount to 8 or 9 percent, when the "returns" of the system are simply given by the growth rate of aggregate wage income. Optimal equity savings are zero for the two lowest income quintiles. Thereafter they increase up to a value of 10 percent for the top quintile. For the sake of comparison, optimal plans have also been derived for HARA preferences. It turns out that the identification of a parameter constellation that leads to a reasonable outcome is not entirely straightforward. E. g. the parameter constellation that has ex ante been chosen as a baseline case leads to very high saving rates that decrease with income. Nevertheless, there exist parameter 
constellations for which optimal plans are a priori reasonable. Two major differences between these plans and optimal plans under lexicographic preferences have been identified. First, the ratio of optimal PAYGO contribution rates to total saving rates is much higher under lexicographic preferences due to loss aversion. Second, lexicographic loss aversion preferences suggest much lower equity investments for the three lower income quintiles. Such low equity investments are consistent with individuals' actually observed portfolio choices in this income range.

In light of the results of this paper, current PAYGO contribution rates for the US, amounting to 12.4 percent, are not too far away from being optimal. To make the current Social Security system sustainable, it would be necessary to reduce benefit guarantees, however. The analysis of this paper makes the case for the fact that individuals would be better off with a partial reform leading to a PAYGO system without benefit guarantees than with a radical reform completely abandoning the PAYGO system.

Future research should extend the analysis of this paper to a setting with multiple periods where labor income is risky and follows a typical inverted U-shape. This allows to study the paths of contribution rates over time. Moreover, optimal contribution rates of the PAYGO system should be considered in the presence of redistributive goals. A further important issue is the study of transitions. 


\section{References}

Baxter, Marianne, and King, Robert G. (2001), "The Role of International Investment in a Privatized Social Security System," in: Campbell, John Y., and Feldstein, Martin (eds.), Risk Aspects of Investment-Based Social Security Reform, The University of Chicago Press, Chicago, pp. 371-429.

Binswanger, Johannes (2004), "Savings and Portfolio Choices with Three Risky Assets under Lexicographic Loss Aversion Preferences," Working Paper.

- (2005), "Understanding the Cross Section of Savings and Portfolio Choices," GREMAQ Working Paper, available at

http://www-gremaq.univ-tlse1.fr/perso/binswanger/working_papers/Standard2P.pdf.

Board of Trustees (2005), The 2005 Annual Report of the Board of Trustees of the Federal Old-Age and Survivors Insurance and Disability Insurance Trust Funds, Washington, D.C., http://www.ssa.gov/OACT/TR/TR05.

Campbell, John Y., Cocco, João F., Gomes, Francisco J., and Maenhout, Pascal J. (2001), "Investing Retirement Wealth: A Life-Cycle Model," in: Campbell, John Y., and Feldstein, Martin (eds.), Risk Aspects of Investment-Based Social Security Reform, The University of Chicago Press, Chicago, pp. 439-73.

Cass, David, and Stiglitz, Joseph E. (1970), "The Structure of Investor Preferences and Asset Returns, and Separability in Portfolio Allocation: A Contribution to the Pure Theory of Mutual Funds," Journal of Economic Theory, 2, pp. 122-160.

Dynan, Karen E., Skinner, Jonathan and Zeldes, Stephen P. (2004), "Do the Rich Save More?" Journal of Political Economy, 112(2), pp. 397-444. 
Eeckhoudt, Louis, and Gollier, Christian (2001), "Are Independent Optimal Risks Substitutes?" IDEI Working Paper.

Gollier, Christian (2001), The Economics of Risk and Time, MIT Press, Cambdrige, Mass.

- (2005), "Intergenerational Risk Sharing and Risk Taking of a Pension Fund," mimeo.

Gomes, Francisco, and Michaelides, Alexander (2003), "Portfolio Choice with Internal Habit Formation: A Life-Cycle Model with Uninsurable Labor Income Risk," Review of Economic Dynamics, 6, pp. 729-766.

Haliassos, Michael (2002), "Stockholding: Recent Lessons from Theory and Computations," in: Guiso, Luigi, Haliassos, Michael, and Japelli, Tullio (eds.), Stockholding in Europe, Palgrave Macmillian Press, Hampshire, pp. 30-51.

Munnell, Alicia H. (2004), "A Bird's Eye View of the Social Security Debate," An Issue in Brief, Center for Retirement Research at Boston College, December 2004, 25.

Poterba, James M. (2004), "Portfolio Risk and Self-Directed Retirement Saving Programmes," Economic Journal, Vol. 114, Issue 494, pp. 26-51.

_, Rauh, Joshua, Venti, Steven and Wise David (2003), "Utility Evaluation of Risk in Retirement Saving Accounts," NBER Working Paper 9892.

Shiller, Robert J. (2005a), "The Life-Cycle Personal Accounts Proposal for Social Security: An Evaluation,” NBER Working Paper 11300.

- (2005b), Irrational Exuberance, $2^{\text {nd }}$ Edition, Princeton University Press, Princeton. 
Tversky, Amos, and Kahneman, Daniel (1991), "Loss Aversion in Riskless Choice: A Reference-Dependent Model," The Quarterly Journal of Economics, 106(4), pp. 10391061. 


\title{
CESifo Working Paper Series
}

\author{
(for full list see www.cesifo-group.de)
}

1509 Jean Hindriks and Ben Lockwood, Decentralization and Electoral Accountability: Incentives, Separation, and Voter Welfare, July 2005

1510 Michelle R. Garfinkel, Stergios Skaperdas and Constantinos Syropoulos, Globalization and Domestic Conflict, July 2005

1511 Jesús Crespo-Cuaresma, Balázs Égert and Ronald MacDonald, Non-Linear Exchange Rate Dynamics in Target Zones: A Bumpy Road towards a Honeymoon - Some Evidence from the ERM, ERM2 and Selected New EU Member States, July 2005

1512 David S. Evans and Michael Salinger, Curing Sinus Headaches and Tying Law: An Empirical Analysis of Bundling Decongestants and Pain Relievers, August 2005

1513 Christian Keuschnigg and Martin D. Dietz, A Growth Oriented Dual Income Tax, July 2005

1514 Fahad Khalil, David Martimort and Bruno Parigi, Monitoring a Common Agent: Implications for Financial Contracting, August 2005

1515 Volker Grossmann and Panu Poutvaara, Pareto-Improving Bequest Taxation, August 2005

1516 Lars P. Feld and Emmanuelle Reulier, Strategic Tax Competition in Switzerland: Evidence from a Panel of the Swiss Cantons, August 2005

1517 Kira Boerner and Silke Uebelmesser, Migration and the Welfare State: The Economic Power of the Non-Voter?, August 2005

1518 Gabriela Schütz, Heinrich W. Ursprung and Ludger Wößmann, Education Policy and Equality of Opportunity, August 2005

1519 David S. Evans and Michael A. Salinger, Curing Sinus Headaches and Tying Law: An Empirical Analysis of Bundling Decongestants and Pain Relievers, August 2005

1520 Michel Beine, Paul De Grauwe and Marianna Grimaldi, The Impact of FX Central Bank Intervention in a Noise Trading Framework, August 2005

1521 Volker Meier and Matthias Wrede, Pension, Fertility, and Education, August 2005

1522 Saku Aura and Thomas Davidoff, Optimal Commodity Taxation when Land and Structures must be Taxed at the Same Rate, August 2005

1523 Andreas Haufler and Søren Bo Nielsen, Merger Policy to Promote 'Global Players’? A Simple Model, August 2005 
1524 Frederick van der Ploeg, The Making of Cultural Policy: A European Perspective, August 2005

1525 Alexander Kemnitz, Can Immigrant Employment Alleviate the Demographic Burden? The Role of Union Centralization, August 2005

1526 Baoline Chen and Peter A. Zadrozny, Estimated U.S. Manufacturing Production Capital and Technology Based on an Estimated Dynamic Economic Model, August 2005

1527 Marcel Gérard, Multijurisdictional Firms and Governments' Strategies under Alternative Tax Designs, August 2005

1528 Joerg Breitscheidel and Hans Gersbach, Self-Financing Environmental Mechanisms, August 2005

1529 Giorgio Fazio, Ronald MacDonald and Jacques Mélitz, Trade Costs, Trade Balances and Current Accounts: An Application of Gravity to Multilateral Trade, August 2005

1530 Thomas Christiaans, Thomas Eichner and Ruediger Pethig, A Micro-Level 'Consumer Approach’ to Species Population Dynamics, August 2005

1531 Samuel Hanson, M. Hashem Pesaran and Til Schuermann, Firm Heterogeneity and Credit Risk Diversification, August 2005

1532 Mark Mink and Jakob de Haan, Has the Stability and Growth Pact Impeded Political Budget Cycles in the European Union?, September 2005

1533 Roberta Colavecchio, Declan Curran and Michael Funke, Drifting Together or Falling Apart? The Empirics of Regional Economic Growth in Post-Unification Germany, September 2005

1534 Kai A. Konrad and Stergios Skaperdas, Succession Rules and Leadership Rents, September 2005

1535 Robert Dur and Amihai Glazer, The Desire for Impact, September 2005

1536 Wolfgang Buchholz and Wolfgang Peters, Justifying the Lindahl Solution as an Outcome of Fair Cooperation, September 2005

1537 Pieter A. Gautier, Coen N. Teulings and Aico van Vuuren, On-the-Job Search and Sorting, September 2005

1538 Leif Danziger, Output Effects of Inflation with Fixed Price- and Quantity-Adjustment Costs, September 2005

1539 Gerhard Glomm, Juergen Jung, Changmin Lee and Chung Tran, Public Pensions and Capital Accumulation: The Case of Brazil, September 2005

1540 Yvonne Adema, Lex Meijdam and Harrie A. A. Verbon, The International Spillover Effects of Pension Reform, September 2005 
1541 Richard Disney, Household Saving Rates and the Design of Social Security Programmes: Evidence from a Country Panel, September 2005

1542 David Dorn and Alfonso Sousa-Poza, Early Retirement: Free Choice or Forced Decision?, September 2005

1543 Clara Graziano and Annalisa Luporini, Ownership Concentration, Monitoring and Optimal Board Structure, September 2005

1544 Panu Poutvaara, Social Security Incentives, Human Capital Investment and Mobility of Labor, September 2005

1545 Kjell Erik Lommerud, Frode Meland and Odd Rune Straume, Can Deunionization Lead to International Outsourcing?, September 2005

1546 Robert Inklaar, Richard Jong-A-Pin and Jakob de Haan, Trade and Business Cycle Synchronization in OECD Countries: A Re-examination, September 2005

1547 Randall K. Filer and Marjorie Honig, Endogenous Pensions and Retirement Behavior, September 2005

1548 M. Hashem Pesaran, Til Schuermann and Bjoern-Jakob Treutler, Global Business Cycles and Credit Risk, September 2005

1549 Ruediger Pethig, Nonlinear Production, Abatement, Pollution and Materials Balance Reconsidered, September 2005

1550 Antonis Adam and Thomas Moutos, Turkish Delight for Some, Cold Turkey for Others?: The Effects of the EU-Turkey Customs Union, September 2005

1551 Peter Birch Sørensen, Dual Income Taxation: Why and how?, September 2005

1552 Kurt R. Brekke, Robert Nuscheler and Odd Rune Straume, Gatekeeping in Health Care, September 2005

1553 Maarten Bosker, Steven Brakman, Harry Garretsen and Marc Schramm, Looking for Multiple Equilibria when Geography Matters: German City Growth and the WWII Shock, September 2005

1554 Paul W. J. de Bijl, Structural Separation and Access in Telecommunications Markets, September 2005

1555 Ueli Grob and Stefan C. Wolter, Demographic Change and Public Education Spending: A Conflict between Young and Old?, October 2005

1556 Alberto Alesina and Guido Tabellini, Why is Fiscal Policy often Procyclical?, October 2005

1557 Piotr Wdowinski, Financial Markets and Economic Growth in Poland: Simulations with an Econometric Model, October 2005 
1558 Peter Egger, Mario Larch, Michael Pfaffermayr and Janette Walde, Small Sample Properties of Maximum Likelihood Versus Generalized Method of Moments Based Tests for Spatially Autocorrelated Errors, October 2005

1559 Marie-Laure Breuillé and Robert J. Gary-Bobo, Sharing Budgetary Austerity under Free Mobility and Asymmetric Information: An Optimal Regulation Approach to Fiscal Federalism, October 2005

1560 Robert Dur and Amihai Glazer, Subsidizing Enjoyable Education, October 2005

1561 Carlo Altavilla and Paul De Grauwe, Non-Linearities in the Relation between the Exchange Rate and its Fundamentals, October 2005

1562 Josef Falkinger and Volker Grossmann, Distribution of Natural Resources, Entrepreneurship, and Economic Development: Growth Dynamics with Two Elites, October 2005

$1563 \mathrm{Yu}-\mathrm{Fu}$ Chen and Michael Funke, Product Market Competition, Investment and Employment-Abundant versus Job-Poor Growth: A Real Options Perspective, October 2005

1564 Kai A. Konrad and Dan Kovenock, Equilibrium and Efficiency in the Tug-of-War, October 2005

1565 Joerg Breitung and M. Hashem Pesaran, Unit Roots and Cointegration in Panels, October 2005

1566 Steven Brakman, Harry Garretsen and Marc Schramm, Putting New Economic Geography to the Test: Free-ness of Trade and Agglomeration in the EU Regions, October 2005

1567 Robert Haveman, Karen Holden, Barbara Wolfe and Andrei Romanov, Assessing the Maintenance of Savings Sufficiency Over the First Decade of Retirement, October 2005

1568 Hans Fehr and Christian Habermann, Risk Sharing and Efficiency Implications of Progressive Pension Arrangements, October 2005

1569 Jovan Žamac, Pension Design when Fertility Fluctuates: The Role of Capital Mobility and Education Financing, October 2005

1570 Piotr Wdowinski and Aneta Zglinska-Pietrzak, The Warsaw Stock Exchange Index WIG: Modelling and Forecasting, October 2005

1571 J. Ignacio Conde-Ruiz, Vincenzo Galasso and Paola Profeta, Early Retirement and Social Security: A Long Term Perspective, October 2005

1572 Johannes Binswanger, Risk Management of Pension Systems from the Perspective of Loss Aversion, October 2005 